\title{
EFL Instructors' Perceptions of Blackboard Learning Management System (LMS) at University Level
}

\author{
Thaer Issa Tawalbeh ${ }^{1}$ \\ ${ }^{1}$ English Language Center, Taif University, Taif, Kingdom of Saudi Arabia \\ Correspondence: Thaer Issa Tawalbeh, English Language Center, Taif University, Building No. 7000, P.O Box \\ 888, Zip Code: 21974. Tel: 966-599-234-100. E-mail: rahafthaer2003@gmail.com
}

Received: October 22, 2017 Accepted: December 1, 2017 Online Published: December 2, 2017

doi: $10.5539 /$ elt.v11n1p1 URL: http://doi.org/10.5539/elt.v11n1p1

\begin{abstract}
The present paper aims to investigate EFL instructors' perceptions of Blackboard learning management system (LMS) at Taif University in Saudi Arabia. To achieve this purposes, the researcher attempted to answer two questions. The first question investigates EFL instructors' perceptions of Blackboard LMS. The second question aims to identify instructors' suggestions to overcome difficulties encountered while using the system. A questionnaire of 4- Likert Scale was used to gather data from one hundred and two instructors to answer the first question, and content analysis was used to answer the second question. The collected data were analyzed in the form of descriptive statistics. The results, on one hand, revealed that $75 \%$ of the instructors have not used Blackboard technology before coming to university, which would affect their perceptions of the system. It was also evident that most of the instructors believe that the different features of Blackboard LMS are either poor or very poor. In addition, the instructors, in most of their responses to the functionalities of using the Blackboard LMS, rarely or never used the system. On the other hand, the results revealed that the instructors have a positive attitude towards the system in terms of its impact on learning, which can be the starting point to help them be familiarized more with the system's features and functionalities through professional development. Based on the results, the researcher presented a number of conclusions and recommendations.
\end{abstract}

Keywords: blackboard learning management system, English as a foreign language, perceptions, Taif University

\section{Introduction and Theoretical Background}

In order to facilitate students' learning, instructors may use a variety of teaching techniques and methods to provide learners with better learning opportunities. In this context, instructors may use the Blackboard technology as a tool to aid learners to be more motivated and actively involved in the learning process. Blackboard is a Web-based learning tool to post information, documents, assignments, and announcements. It may allow real-time activities such as chat rooms that can be used for student-to-instructor and instructor-to student document transfer (Servonsky, Lawrence, \& Bretha, 2005; Larkin \& Belson, 2005).

\subsection{An overview of Blackboard Learning Management System (LMS)}

Due to the rapid development of information systems in higher education, academic institutions around the world are investing heavily in various learning management systems LMS to deliver and manage e-learning services (Liaw, 2008; Paechter et al., 2010; Chang, 2014; Caputi \& Garrido, 2015). Indeed, LMS including the Blackboard are considered among the most commonly used and useful types of e-learning systems for both students and instructors in academic institutions (Sun et al., 2008; Liaw, 2008; Chang, 2014). For instructors, LMS provides different online course management features which allow instructors to post announcements and grades as well as manage quizzes and exams (Ngai et al., 2007; Chang, 2014). For students, LMS has improved their online communication with the instructors by motivating them to play an active role in the learning process, rather than playing a passive role of receiving information through traditional methods, such as instructors and textbooks (Liaw, 2008; Tella, 2011). According to Beatty and Connie (2006), Blackboard is one of the leading commercial learning management systems LMS software packages used by North American and European universities. This learning system is a software application to facilitate teaching and learning. The system has capabilities of instruction, communication and assessment. Hall (2006) argues that successful implementation of LMS depends on providing training and support for instructors, and on the level of student active engagement and student and instructor satisfaction with the LMS used. 


\subsection{Challenges, Advantages and Disadvantages of Blackboard}

Servonsky, Lawrence and Bretha (2005) pointed out some challenges using the Blackboard. They stated that preparing an online course requires more planning and more preparation time for instructional materials. It takes much more time to prepare a lecture using Blackboard than it does for the traditional face-to-face teaching experience. In addition, content must be reviewed and updated constantly as technology changes. This includes downloading or reviewing documents, making changes, and referencing and reposting the documents. Meanwhile, the advantages and disadvantages of e-learning have been discussed in many articles. Bouhnik and Marcus (2006) stated that e-learning has four advantages: a) freedom to decide when each online lesson will be learned. b) lack of dependence on the time constraints of the lecturer. c) freedom to express thoughts, and ask questions, without limitations. d) the accessibility to the course's online materials at students' own election. Furthermore, Capper (2001) stated the following benefits: a) any time: a participant can access the learning program at any time that is convenient. b) any place: the participants do not have to meet. c) asynchronous interaction: interactions can be more succinct and discussion can stay more on-track. d) group collaboration: electronic messaging creates new opportunities for groups to work together by creating shared electronic conversations and discussions. e) new educational approaches: many new options and learning strategies become economically feasible through online courses. Online courses can also provide unique opportunities for teachers and learners to share innovations in their own work with the immediate support of electronic groups. Meanwhile, Bouhnik and Marcus (2006) stated that students' e-learning dissatisfaction was based the following disadvantages: a) lack of a firm framework to encourage students to learn. b) a high level of self-discipline or self-direct is required. c) absence of a learning atmosphere in e-learning systems. d) the distance-learning format minimizes the level of contact, as well as the level of discussion, among students. In other words, e-learning lacks interpersonal and direct interaction among students and teachers. e) the learning process is less efficient. When compared to the face-to-face learning format, e-learning requires students to dedicate more time to learn the subject matter.

\subsection{Problem Statement and Objective}

Based on the researcher's professional contact with EFL instructors, it has been noticed that they have certain concerns and sometimes complaints in dealing with the use of technology in the classroom in general and with the Blackboard LMS in specific. Many instructors have difficulties with the Blackboard system and its features and functionalities. Others have concerns related to the impact of the Blackboard LMS on learning. They need to be aware of characteristics of the system so that they can use it effectively. The researcher believes that it is worthwhile to investigate the instructors' perceptions to be better able to enhance students' learning using the Blackboard technology.

\subsection{Research Questions}

This paper attempts to answer the following questions:

1- What are the EFL instructors' perceptions of the Blackboard LMS at Taif University?

This question includes the following sub questions directed to the instructors in the questionnaire:

a. What is your previous experience with the Blackboard LMS: Have you used Blackboard before coming to University?

b. What is your evaluation of Blackboard LMS across different features?

c. What is the frequency of use of functionalities in Blackboard LMS?

d. What is the Blackboard LMS impact on learning?

2- What difficulties do the instructors encounter while dealing with the Blackboard LMS and their suggestions to overcome these difficulties?

\subsection{Significance of the Study}

The results of this paper will be important to:

- EFL instructors to utilize the suggestions presented to overcome potential difficulties while using Blackboard LMS.

- The Quality Assurance and Professional Development Unit to consider the challenges instructors encounter while using the Blackboard technology in their plans of instructors' professional development.

- EFL practitioners to consider conclusions and recommendations based on the results of the study to conduct further research. 


\subsection{Definition of Terms}

The following term will have the associated meaning whenever it appears in this paper:

- Blackboard Learning Management System: an e-learning system that includes a set of features and functionalities that helps teachers and students to communicate effectively in an academic setting and enhance students' learning opportunities.

\section{Review of Related Studies}

Many studies have provided evidence that using Blackboard LMS have a direct impact on students' learning (Servonsky et al., 2005; Liaw, 2008). Servonsky et al. (2005) found that the Blackboard platform allows for synchronous, real-time activities such as chat rooms, and asynchronous, delayed, activities such as discussion boards and digital drop boxes that can be used for student-to-instructor and instructor-to-student document transfer. Liaw (2008) investigated learners' satisfaction, behavioral intention and the effectiveness of Blackboard e-learning system. The results revealed that perceived self-efficacy is a critical factor that influences learners' satisfaction with the Blackboard e- learning system. Perceived usefulness and perceived satisfaction both contribute to the learners' behavioral intention to use the e-learning system. Furthermore, e-learning effectiveness can be influenced by multimedia instruction, interactive learning activities, and e- learning system quality.

Within LMS context, other studies were conducted to investigate the perceived usefulness (pu) of Blackboard LMS (Limayem \& Cheung, 2008; Lee, 2010; Roca et al., 2006; Sørebø \& Sørebø, 2009). Limayem and Cheung (2008) have found that pu significantly influences satisfaction and continuance intention to use the Blackboard system among first-year business students in one university. Similar results have been obtained from Lee (2010), who has found that pu influences satisfaction and continuance intention among students who are offered e-learning services in the continuing education program of National Pingtung University in Taiwan. Roca et al. (2006) have found that pu is one of the determinants of user satisfaction toward e-Learning services in different international agencies of the United Nations. Sørebø and Sørebø (2009) have found that pu significantly influences satisfaction among university teachers who have utilized e-learning technology in connection with on-site courses in Norway. In this study, they hypothesized that the more useful the Blackboard system is, the more university instructors will be satisfied and also inclined to continue using it.

Two studies were conducted to examine students' satisfaction with the Blackboard LMS and the factors that predict their levels of satisfaction (Tella, 2012; Mouakket \& Anissa, 2015). Tella (2012) found that all the system-related factors focused upon in the study, i.e. net benefits, self-regulated learning, content quality, teaching/learning quality, system quality, and service quality, correlated with users' satisfaction with the Blackboard system and the factors jointly predicted $54 \%$ of variations in the students' satisfaction. Based on these findings, it was recommended that the university needs to improve the support services provided for users of the system. The Blackboard support staff should always consider making themselves available for assistance bearing in mind that the system is all about technology which can develop technical faults at any time. Mouakket and Anissa (2015) investigated the factors affecting Blackboard usage by university instructors to understand their continuance intention to use the Blackboard system as a popular LMS. The study revealed that pu affected satisfaction of the Blackboard system. Both pu and satisfaction affected instructors' continuance intentions to use the Blackboard system. User-interface design affected both pu and satisfaction. Technical support influenced pu. Training influenced pu, but it had no influence on satisfaction. Computer self-efficacy had no influence on pu.

Servonsky et al. (2005) in their study on the impact of Blackboard LMS on students' learning found that there are challenges of using this system. While the overall acceptance of the curriculum using this platform has been excellent, distance education utilizing web-based technologies presents a unique opportunity for continuity of content between different sessions of the same course, preparing an online course for distance education requires more precise planning and more preparation time for instructional materials. It takes much more time to prepare a lecture for a distance education class than it does to prepare a lecture for the traditional face-to-face teaching experience. In addition, real-time interfacing by typing is much slower than verbal communication.

\section{Method}

In this section, the researcher describes the methodology followed to collect and analyzes data. It shows how population and sample of the study were identified, how validity and reliability of the study instrument was checked, procedures followed to conduct the study, and statistical analysis used to analyze the data.

\subsection{Population and Sample Selection}

The study population comprised two hundred instructors teaching English in the preparatory year at Taif 
University in the second semester of the academic year 2016-2017. One hundred and two instructors responded to the questionnaire. This represents $51 \%$ of the whole population.

\subsection{Study Instrument}

The researcher adopted the questionnaire used by Carvalho, Nelson and Joaquim (2011) in their study to evaluate students' perceptions of blackboard. A 4- Likert scale was used to investigate the EFL instructors' perceptions of Blackboard technology at Taif University (Appendix A).

\subsection{Instrument Validity and Reliability}

It can be argued that the instrument is valid since it has been developed and used by specialists in this field. However, six EFL specialists were kindly requested to check if the items were appropriate and relevant to the domains and context. In addition, in order to check the instrument reliability, the checklist was distributed to 20 EFL instructors. They were asked to respond to the questionnaire. It was then distributed to them again after two weeks. The results were analyzed and the correlation coefficient (Pearson) between the previous and post time was 0.89 .The Cronbach alpha reliability for the checklist was .87 .

\subsection{Study Procedures}

The researcher formally requested the approval of the preparatory year dean to conduct the study and distribute the questionnaire to the EFL instructors. The instrument was checked for validity and reliability. Having the consent of the participants, the questionnaire was distributed and collected after being filled in. The researcher processed the results using the appropriate statistical methods to get the findings. Based on the findings, relevant conclusions and recommendations were drawn.

\subsection{Statistical Analysis}

Descriptive statistical analysis was used to answer the first question which aimed to investigate the EFL instructors' perceptions of Blackboard as a LMS. Content analysis was used to answer the second question which aimed to identify the instructors' suggestions to overcome difficulties they may encounter with the Blackboard LMS.

\section{Results and Discussion}

To answer the first question related to the instructors' perceptions of the Blackboard LMS, the results of the first sub question addressing the instructors' previous experience with the Blackboard shows that $75 \%$ of the instructors have not used Blackboard before coming to university. Only $25 \%$ of them used it in professional training, in another university, or in a secondary school. This result would affect the instructors' perceptions specified in the other sub questions as clarified below.

To answer the second sub question related to the instructors' evaluation of Blackboard across different features, Table 1 shows frequencies and percentages of the instructors' evaluations of the Blackboard LMS across different features.

Table 1. Frequencies and percentages of the instructors' evaluations of Blackboard LMS across different features

\begin{tabular}{llllllllll}
\hline No. & Item & \multicolumn{7}{c}{ Frequency } & \multicolumn{7}{c}{ Percentage } \\
& & $\mathbf{1}$ & $\mathbf{2}$ & $\mathbf{3}$ & $\mathbf{4}$ & $\mathbf{1}$ & $\mathbf{2}$ & $\mathbf{3}$ & $\mathbf{4}$ \\
\hline 1 & Time required to learn the system & 6 & 13 & 55 & 28 & 5.9 & 12.7 & 53.9 & 27.5 \\
2 & Ease in logging in & 2 & 13 & 33 & 54 & 2.0 & 12.7 & 32.4 & 52.9 \\
3 & Visual appearance & 4 & 11 & 50 & 37 & 3.9 & 10.8 & 49.0 & 36.3 \\
4 & Ease of access to materials & 3 & 16 & 44 & 39 & 2.9 & 15.7 & 43.1 & 28.2 \\
5 & Organization of materials & 3 & 19 & 52 & 28 & 2.9 & 18.6 & 15.0 & 27.5 \\
6 & Search tool & 4 & 18 & 55 & 25 & 3.9 & 17.6 & 53.9 & 24.5 \\
7 & Internal help tool & 3 & 21 & 53 & 25 & 2.9 & 20.6 & 52.0 & 24.5 \\
8 & Ease in assignment upload & 6 & 15 & 40 & 41 & 5.9 & 14.7 & 39.2 & 40.2 \\
9 & Participation in forums & 8 & 21 & 54 & 19 & 7.8 & 20.6 & 52.9 & 18.6 \\
\hline
\end{tabular}

Key: $1=$ very good; $2=$ good; $3=$ poor; $4=$ very poor. 
It is evident from the frequencies and percentages in the table above that most of the instructors believe that the different features of Blackboard LMS are either poor or very poor. This could be explained on the ground that $75 \%$ of the instructors have no previous experience with the Blackboard LMS as they have not used it before coming to university. Only $25 \%$ of the instructors used the Blackboard in their professional training, at university or school before. This unfamiliarity with the system could lead to their poor evaluation of the features they responded to. Another reason might be due to the fact that they have not received enough training that could help them deal easily with the different features of the Blackboard LMS. In addition, this system has been introduced recently at university.

To discuss the second sub question related to the instructors' frequency of use of functionalities in Blackboard LMS, tables 2 shows frequency and percentage of the instructors' use of functionalities in Blackboard LMS.

Table 2. Frequency and percentage of the instructors' use of functionalities in Blackboard LMS

\begin{tabular}{llllllllll}
\hline No. & Item & \multicolumn{7}{c}{ Frequency } & \multicolumn{7}{l}{ Percentage } \\
& & $\mathbf{1}$ & $\mathbf{2}$ & $\mathbf{3}$ & $\mathbf{4}$ & $\mathbf{1}$ & $\mathbf{2}$ & $\mathbf{3}$ & $\mathbf{4}$ \\
\hline 1 & Upload course materials (texts, activities, handouts) & 3 & 8 & 50 & 41 & 2.9 & 7.8 & 49.0 & 40.2 \\
2 & Upload course announcements & 7 & 16 & 30 & 49 & 6.9 & 15.7 & 29.4 & 48.0 \\
3 & Enter course grades & 24 & 16 & 44 & 18 & 23.5 & 15.7 & 43.1 & 17.6 \\
4 & Upload the course syllabus and schedule & 14 & 22 & 34 & 32 & 13.7 & 21.6 & 33.3 & 31.4 \\
5 & Send assignments & 7 & 21 & 35 & 39 & 6.9 & 20.6 & 34.3 & 28.2 \\
6 & Check students' responses & 9 & 21 & 36 & 36 & 8.8 & 20.6 & 35.3 & 35.3 \\
7 & Give quiz tests & 10 & 21 & 38 & 33 & 9.8 & 20.6 & 37.3 & 32.4 \\
8 & Send emails to students & 25 & 25 & 28 & 24 & 24.5 & 24.5 & 27.5 & 23.5 \\
9 & Upload course surveys & 6 & 12 & 39 & 45 & 5.9 & 11.8 & 38.2 & 44.1 \\
10 & Arrange an online appointment with students & 8 & 16 & 36 & 42 & 7.8 & 15.6 & 35.2 & 41.1 \\
11 & Participate in forum discussions & 4 & 8 & 32 & 58 & 3.9 & 7.8 & 31.3 & 56.8 \\
12 & Participate in course chat room or virtual classroom & 2 & 9 & 25 & 66 & 1.9 & 8.8 & 24.5 & 64.7 \\
\hline
\end{tabular}

Key: $1=$ very often; $2=$ sometimes; $3=$ rarely; $4=$ never.

It is clear from the frequencies and percentages in the table above that instructors, in most of their responses to the functionalities of using the Blackboard LMS, rarely or never used the system. However, they sometimes used functionalities number 3, 4 and 8 related to entering course grades, uploading course syllabus and schedule, and sending emails to students. These results support the previous results of most of the instructors had no previous experience with the Blackboard technology, did not receive enough training, and the fact that the system has been introduced recently as a learning management system. In addition, this result might be explained on the ground that using the Blackboard as a learning management system is not part of the instructors' performance assessment as they have not been formally requested to use it as part of their teaching process.

As for the third sub question related to the instructors' views of the impact of the Blackboard LMS on learning, Table 3 shows the frequencies and percentages of the instructors' level of agreement on the statements below:

Table 3. Frequency and percentage of the instructors' views of the Blackboard learning impact

\begin{tabular}{lllllllllll}
\hline No. & Item & \multicolumn{7}{c}{ Frequency } & \multicolumn{7}{c}{ Percentage } \\
& & $\mathbf{1}$ & $\mathbf{2}$ & $\mathbf{3}$ & $\mathbf{4}$ & $\mathbf{1}$ & $\mathbf{2}$ & $\mathbf{3}$ & $\mathbf{4}$ \\
\hline 1 & helps me find the information I need & 22 & 53 & 25 & 2 & 21.6 & 52.0 & 24.5 & 2.0 \\
2 & has a positive impact on my teaching & 40 & 51 & 9 & 2 & 39.2 & 50.0 & 8.8 & 2.0 \\
3 & is enough to pass the course & 13 & 44 & 32 & 13 & 12.7 & 31.4 & 43.1 & 12.7 \\
4 & helps me keep up with the course work & 37 & 47 & 14 & 4 & 36.3 & 46.1 & 13.7 & 3.9 \\
\hline
\end{tabular}




\begin{tabular}{llllllllll}
\hline 5 & helps me organize my teaching & 36 & 54 & 9 & 3 & 35.3 & 52.9 & 8.8 & 2.9 \\
6 & serves to download class Power Points & 35 & 50 & 13 & 4 & 34.3 & 49.0 & 12.7 & 3.9 \\
7 & helps with group work & 31 & 47 & 18 & 6 & 30.4 & 46.1 & 17.6 & 5.9 \\
8 & helps to communicate with students & 43 & 47 & 8 & 4 & 42.2 & 46.1 & 7.8 & 3.9 \\
\hline
\end{tabular}

Key: $1=$ strongly agree; $2=$ agree; $3=$ disagree; $4=$ strongly disagree.

It is clear from the table above that the instructors have a positive attitude towards the Blackboard LMS in terms of its impact on learning. The majority believe that it can assist them in the learning process, which can be claimed as the positive image of the whole picture. It is true that the majority have little experience in using the system's features and functionalities. Meanwhile, having this positive attitude can be the starting point to help instructors become familiarized with using the system as a learning tool.

As for the second question regarding the difficulties instructors encounter while using the Blackboard and their suggestions to overcome the difficulties, their responses focused mainly on technical issues such as: logging onto the system; opening files; uploading the targeted materials; uploading assignments; the system taking up a lot of their time; not knowing how to use the system properly as they are not used to it; instructors not registered in the system, and internet access challenges. Other difficulties relevant to students include: a) students who don't know how to use the system properly; b) students who have internet access difficulties; and c) some others have mobiles that do not have the required application to download Blackboard and use it as a learning tool. The instructors suggested that they need enough professional development sessions to be familiarized more with the system features and functionalities, and exchange views of the challenges they encounter and possible ways to overcome them. They also suggested that students need training sessions to familiarize them more with system features and functionalities. Others suggested that using the system should be part of students' performance assessment to motivate them to utilize the Blackboard in their learning.

\section{Conclusions and Recommendations}

The present paper aimed to investigate EFL instructors' perceptions of Blackboard LMS at Taif University, and provide suggestions to overcome potential difficulties instructors encounter while using the system. The results, on one side, revealed that $75 \%$ of the instructors have not used Blackboard before coming to university, which would affect their perceptions of the system. It was also evident that most of the instructors were unfamiliar with the features and functionalities of Blackboard. This could be due to the fact that they have not received enough training that could help them deal easily with the different features and functionalities of the system. On the other hand, the results revealed that the majority of the instructors believe that Blackboard has an obvious impact on learning, which can be the starting point to help them be familiarized more with the system's features and functionalities through professional development. Based on these conclusions, the Quality Assurance and Development Unit in the English Language Center was recommended to consider the results of this paper in their plans of teachers' professional development. It may conduct sessions where the various features and functionalities are made clearer in practice to teachers, and where challenges are discussed and possible solutions are exchanged.

\section{Acknowledgments}

The researcher would like to acknowledge the contribution of the instructors who participated in the questionnaire validity and reliability. Many thanks also go to the instructors who responded to the questionnaire.

\section{References}

Beatty, B., \& Connie U. (2006). Faculty perspectives on moving from Blackboard to the Moodle learning management system. TechTrends, 50(4), 36-45. https://doi.org/10.1007/s11528-006-0036-y

Bouhnik, D., \& Marcus, T. (2006). Interaction in distance-learning courses. Journal of the American Society Information Science and Technology, 57(3), 299-305. https://doi.org/10.1002/asi.20277

Capper, J. (2001). E-learning growth and promise for the developing world. Tech Know Logia, http://www.techknowlogia. org. Retrieved July 20, 2007

Caputi, V., \& Garrido, A. (2015). Student-oriented planning of e-learning contents for Moodle. Journal of Network and Computer Applications, 53, 115-127. https://doi.org/10.1016/j.jnca.2015.04.001 
Carvalho, A., Nelson, A., \& Joaquim, S. (2011). Students' perceptions of Blackboard and Moodle in a Prtoguese university, British Journal of Educational Technology, 42(5), 824-841. https://doi.org/10.1111/j.1467-8535.2010.01097.x

Chang, C. C. (2014). Exploring the determinants of e-Learning systems continuance intention in academic libraries, Library Management, 34(1/2), 40-55. https://doi.org/10.1108/01435121311298261

Hall, C. (2006). Lighting a fire or filling a pail? Users' perceptions of a virtual learning environment. Survey Report, University of Swansea. Retrieved February 28, 2008, from http://learninglab.swan.ac.uk/Downloads/User_Survey_Report\%201.1.pdf

Larkin, T. L., \& Belson, S., I. (2005). Blackboard technologies: A Vehicle to promote students' motivation in physics, ProQuest, Journal of Stem Education: Innovation and Research, 6(1), 14-27.

Liaw, S. (2008). Investigating students' perceived satisfaction, behavioral intention, and effectiveness of e-Learning: a case study of the Blackboard system. Computers \& Education, 51(2), 864-873. https://doi.org/10.1016/j.compedu.2007.09.005

Mouakket, S., \& Anissa, B. (2015). Investigating the factors influencing continuance usage intention of learning management systems by University instructors. The Blackboard Case. International Journal of Web Information Systems, 11(4), 491-509. https://doi.org/10.1108/IJWIS-03-2015-0008

Ngai, E. W. T., Poon, J. K. L., \& Chan, Y. H. C. (2007). Empirical examination of the adoption of WebCT using TAM. Computers \& Education, 48(2), 250-267. https://doi.org/10.1016/j.compedu.2004.11.007

Paechter, M., Maier, B., \& Macher, D. (2010). Students' expectations of, and experiences in e-learning: their relation to learning achievements and course satisfaction. Computers \& Education, 54(1), 222-229. https://doi.org/10.1016/j.compedu.2009.08.005

Servonsky, W. L., \& Bertha, L. (2005). Evaluation of blackboards as a platform for distance education delivery. The ABNF Journal, 132-135.

Sun, P. C., Tsai, R. J., Finger, G., Chen, Y.-Y., \& Yeh, D. (2008). What drives a successful el-earning? An empirical investigation of the critical factors influencing learner satisfaction, Computers \& Education, 50(4), 1183-1202. https://doi.org/10.1016/j.compedu.2006.11.007

Tella, A. (2011). Reliability and factor analysis of a blackboard course management system success: a scale development and validation in an educational context. Journal of Information Technology Education, 10(1), 55-80. https://doi.org/10.28945/1368

Tella, A. (2012). System-related factors that predict students' satisfaction with the blackboard learning system at the University of Botswana. African Journal of Library, Archives and Information Science, 22(1), 41-52.

\section{Appendix A}

\section{Dear colleagues,}

The researcher will carry out a study to investigate EFL instructors' perceptions of Blackboard as a Learning Management System (LMS) to enhance English language learning at Taif University. For this purpose, the researcher seeks your points of view by filling in the questionnaire below by putting $(\checkmark)$ where applicable. Please note that your contribution will be used for research purposes only.

\begin{tabular}{|l|l|l|l|}
\hline \multicolumn{2}{|c|}{ Domains and Items } & \multicolumn{2}{l|}{ Degree } \\
\hline \multicolumn{2}{|c|}{$\begin{array}{l}\text { Domain 1: Your previous experience with the Blackboard LMS: } \\
\text { Have you used Blackboard before coming to Taif University? }\end{array}$} & $\begin{array}{l}\text { Yes } \\
\mathbf{1}\end{array}$ & $\begin{array}{l}\text { No } \\
\mathbf{2}\end{array}$ \\
\hline 1 & In professional training & & \\
\hline 2 & In another university & & \\
\hline 3 & In secondary school & & \\
\hline 4 & No & & \\
\hline
\end{tabular}




\begin{tabular}{|c|c|c|c|c|c|}
\hline \multicolumn{2}{|r|}{ 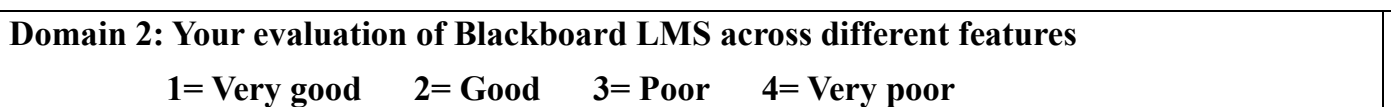 } & 1 & \multirow[t]{2}{*}{2} & \multirow[t]{2}{*}{3} & 4 \\
\hline 1 & Time required to learn the system & & & & \\
\hline 2 & Ease in logging in & & & & \\
\hline 3 & Visual appearance & & & & \\
\hline 4 & Ease of access to materials & & & & \\
\hline 5 & Organization of materials & & & & \\
\hline 6 & Search tool & & & & \\
\hline 7 & Internal help tool & & & & \\
\hline 8 & Ease in assignment upload & & & & \\
\hline 9 & Participation in forums & & & & \\
\hline \multicolumn{2}{|r|}{ Domain 3: Frequency of use of functionalities in Blackboard LMS } & 1 & 2 & 3 & 4 \\
\hline 1 & Upload course materials (texts, activities, handouts) & & & & \\
\hline 2 & Upload course announcements & & & & \\
\hline 3 & Enter course grades & & & & \\
\hline 4 & Upload the course syllabus and schedule & & & & \\
\hline 5 & Send assignments & & & & \\
\hline 6 & Check students' responses & & & & \\
\hline 7 & Give quiz tests & & & & \\
\hline 8 & Send emails to students & & & & \\
\hline 9 & Upload course surveys & & & & \\
\hline 10 & arrange an online appointment with students & & & & \\
\hline 11 & Participate in forum discussions & & & & \\
\hline 12 & Participate in course chat room or virtual classroom & & & & \\
\hline \multicolumn{2}{|r|}{ 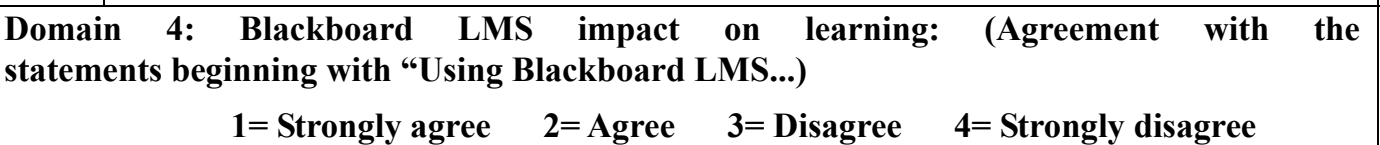 } & 1 & 2 & 3 & 4 \\
\hline 1 & helps me find the information I need. & & & & \\
\hline 2 & has a positive impact on my teaching. & & & & \\
\hline 3 & is enough to pass the course. & & & & \\
\hline 4 & helps me keep up with the course work. & & & & \\
\hline 5 & helps me organize my teaching. & & & & \\
\hline 6 & serves to download class Power Points. & & & & \\
\hline 7 & helps with group work. & & & & \\
\hline 8 & helps to communicate with students. & & & & \\
\hline
\end{tabular}


What difficulties do you face while dealing with the Blackboard LMS?

Your suggestions to overcome the difficulties:

\section{Copyrights}

Copyright for this article is retained by the author(s), with first publication rights granted to the journal.

This is an open-access article distributed under the terms and conditions of the Creative Commons Attribution license (http://creativecommons.org/licenses/by/4.0/). 